\title{
Experimental Investigation and Analysis of Hydroformed Stainless Steel Tubes
}

\author{
Rajiv Selvam ${ }^{1}$, Tanmay Nitin Koche ${ }^{2}$, Sameelur Rahman ${ }^{3}$ and Sheikh Shoaib Hassan ${ }^{4}$ \\ ${ }^{1}$ Assistant Professor, Department of Mechanical Engineering, School of Engineering \& Information Technology, \\ Manipal Academy of Higher Education, Dubai, UAE. \\ ${ }^{2-4}$ Under Graduate Student, Department of Mechanical Engineering, School of Engineering \& Information \\ Technology, Manipal Academy of Higher Education, Dubai, UAE.
}

\begin{abstract}
Background/Objectives: The experimental investigation and analysis were carried on metal bellows made of 304 stainless steel tubes. Methods/Statistical analysis: FEM analysis using ANSYS was done by varying the manufacturing parameters of bellows, such as internal pressure and die stroke to get an optimum crown diameter of the bellows. Findings: An experimental investigation in the form of an optimization is done by varying the manufacturing parameters of metal bellows. Improvements/Applications: Hardness test, forming height vs thickness distribution and micro structure analysis were done to study the hydroforming process.
\end{abstract}

\section{Index Terms}

Bellows, FEM, Hydroforming, Optimization, Parameter

\footnotetext{
Corresponding author : Rajiv Selvam

rajiv.selvam@manipaldubai.com

- Manuscript received May 14, 2018.

- Revised June 5, 2018; Accepted June 7, 2018.

- Date of publication June 30, 2018.

(c) The Academic Society of Convergence Science Inc.

2546-1583 @ 2017 IJEMR. Personal use is permitted, but republication/redistribution requires IJEMR permission.
} 


\section{INTRODUCTION}

Hydroforming is a method of shaping ductile metals into intricate shapes for a wide variety of specific applications. Hydroforming is a very specialized type of metal forming, where high pressurized hydraulic fluid is forced to form the metal at room temperature. Complex and concave shapes can be created with the hydroforming process on to a mandrel or into a die. Hydroforming is commonly used to shape metals such as carbon steel, copper, aluminium, brass and stainless steel. A bellow is a convoluted shell consisting of a series of toroidal shells. Metal bellows have applications in piping systems, automotive exhaust systems, refrigeration, air conditioners and aerospace.

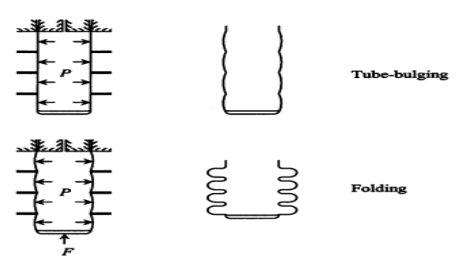

Fig. 1. Manufacturing of metal bellows by hydroforming

One of the functions of bellows is to absorb regular or irregular expansions and contractions in system. Figure 1 shows the manufacturing of metal bellows by hydroforming which has two stages such as bulging and folding [8].

In the tube-bulging process, the equally spaced circular plate dies are set to surround the wall of the tube and the internal pressure increases up to a proper value. In the folding process, while the internal pressure is maintained as a constant value, the axial force is applied along the longitudinal direction of the bulged tube in order to complete the final shape of the metal bellows [10]. Several parameters affect the process, including tube diameter, tube thickness, die stroke (distance between annular plate dies), axial feeding and internal pressure.

Ghader Faraji et al $[1,2]$ have investigated the manufacturing parameters of metal bellows in the material of Phosphor Bronze CuSn6. Rajiv et al [3] have studied the prediction of failure in tube hydroforming process for various models of AISI 1010 steel with and without heat treatment. They concluded that heat treatment has increased the specimen's formability and a vital requirement in metal forming. Majzoobi et al [4] has investigated the parameters of metal bellows made up of fully annealed Phosphor Bronze. He has carried out parametric study by FE only. N. Siva Prasad Varma et al [7] have investigated various types of loading conditions on tubular hydro formed tube material of $\mathrm{Al}-3 \% \mathrm{Mg}$ alloy.

The present work was to analyze the manufacturing parameters by Fininte Element Analysis and check them with experiments. After the experiments, various tests were conducted to study the hydroforming process.

\section{Finite Element Method}

FEM analysis was carried out on the stainless steel pipe of diameter $(\mathrm{d})=100 \mathrm{~mm}$, length $(\mathrm{l})=150 \mathrm{~mm}$ and thickness $\mathrm{t}=0.3 \mathrm{~mm}$ as shown in Figure 2. The material properties of 304 Stainless Steel were taken as density $(\rho)=7860 \mathrm{Kg} / \mathrm{m}^{3}$, Young's modulus (E) $=210 \times 10^{9} \mathrm{~N} / \mathrm{m}^{2}$ and Poisson ratio $(v)=0.3$.

\section{A. Material model}

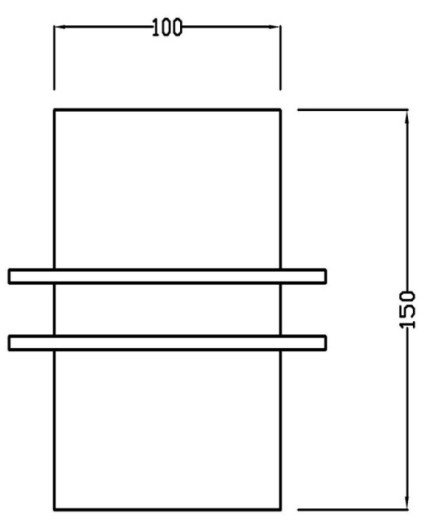

Fig. 2. Stainless Steel Pipe dimensions

By using the thin wall pressure vessel theory, the initial internal pressure for processing the bellows can be estimated by the following equation [5]:

$$
\sigma=(\operatorname{Pxr}) / t
$$

At the yield point:

$\sigma_{\mathrm{y}}=210 \mathrm{Mpa}, \mathrm{r}=50 \mathrm{~mm}, \mathrm{t}=0.3 \mathrm{~mm}$

From Equation (1),

$\sigma=(\operatorname{Pxr}) / t$

One could calculate the required pressure is 0.01677 $\mathrm{N} / \mathrm{mm}^{2}$.

Conduct the analysis by varying the internal pressure and die stroke for constant axial compressive load which is shown in Figure 3. 


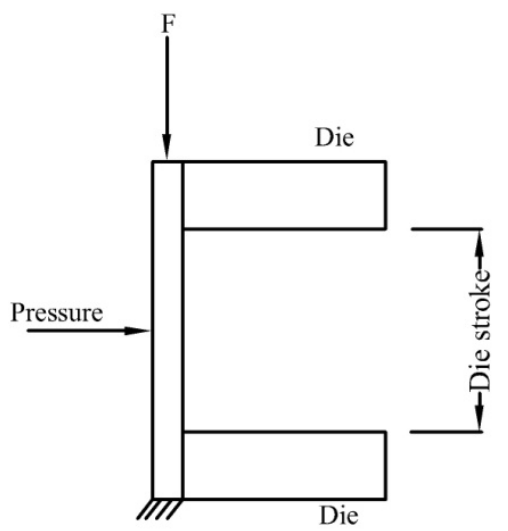

Fig. 3. Process parameter

The FEM process was modelled and analyzed by using ANSYS commercial finite element code. The modelling is done by using the structural SOLID PLANE42 element in axisymmetric method. The SOLID PLANE42 is a quadrilateral element. The meshed model is shown in Figure 4 [9].

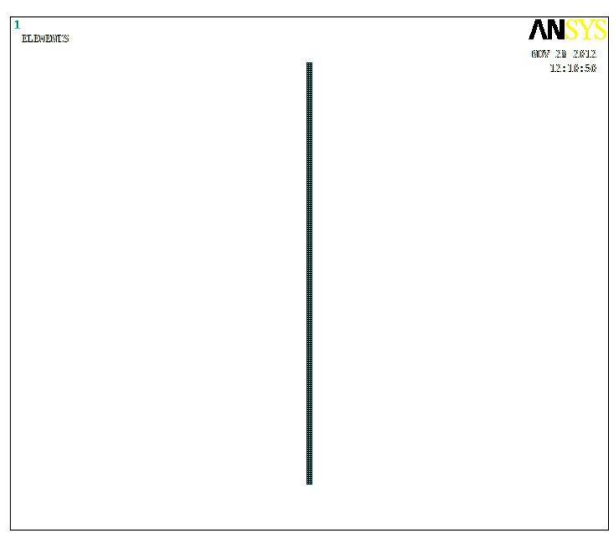

Fig. 4. Meshed Model

\section{B. Boundary conditions}

The job is constraint in the translation radial direction at the outer part of pipe (i.e., at outer line of axisymmetric model) and fixed at the part where die make contact with the pipe. At here the pipe is fully constraints are shown in Figure 5. Consider the contact friction between pipes and die as 0.1 .

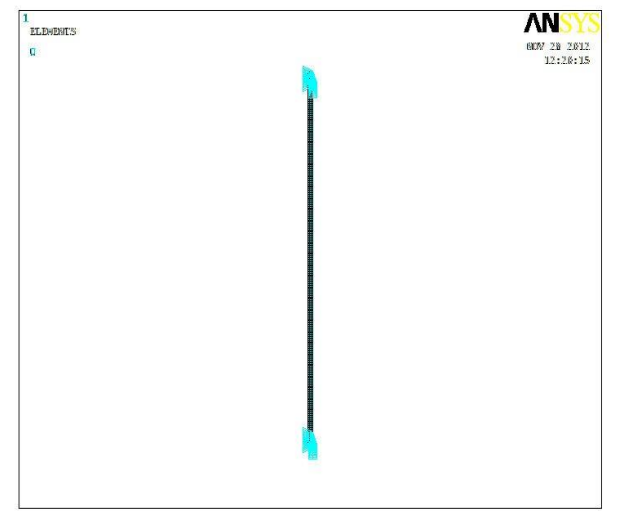

Fig. 5. Boundary conditions

\section{Analysis}

The finite element analysis was performed under the following steps:

During bulging, the length of tube is constant and no axial feeding is applied which is shown in Figure 6. As soon as the internal pressure reaches its maximum value at the end of the bulging step.

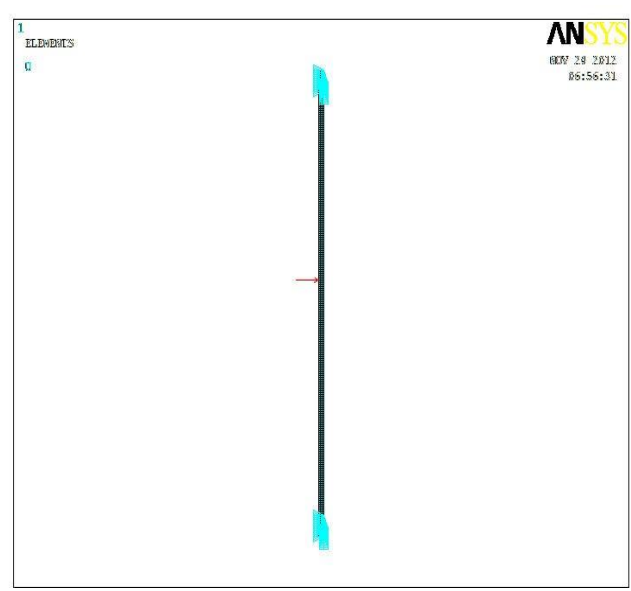

Fig. 6. Bulging stage of analysis

In the Folding stage, an axial feeding is applied to the end of the tube and internal pressure remains constant which is shown in Figure 7.

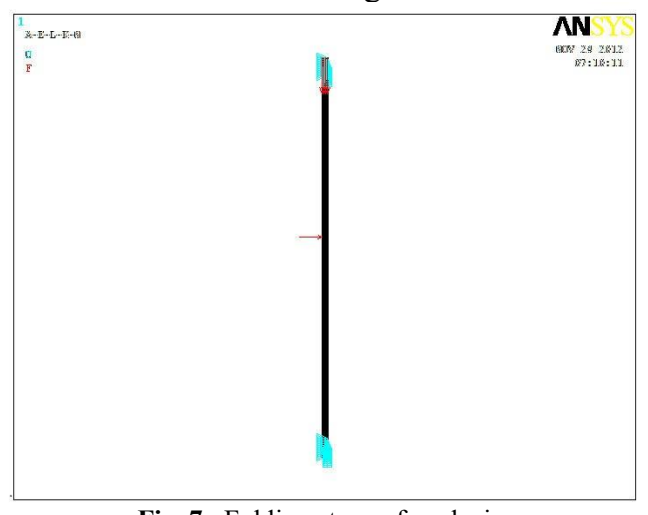

Fig. 7. Folding stage of analysis 
The various pressures used in this analysis are 0.025 , $0.029,0.034,0.039$ and $0.045 \mathrm{~N} / \mathrm{mm}^{2}$. The various die strokes used in this analysis are 20, 22, 24, 26, 28 and $30 \mathrm{~mm}$. For all analysis a constant $245250 \mathrm{~N}$ (25 tonne) of compressive load is used.

Conduct the analysis by varying the die stroke 20, 22, 24, 26, 28 and $30 \mathrm{~mm}$ for a constant internal pressure $0.039 \mathrm{~N} / \mathrm{mm}^{2}$. Then conduct the analysis by varying the internal $0.025,0.029,0.034,0.039$ and $0.045 \mathrm{~N} / \mathrm{mm}^{2}$ for a constant die stroke $30 \mathrm{~mm}$.

\section{EXPERIMENTAL WORK}

The experiment is conducted in the form of optimization to find the best combination of internal pressure and die stroke [6]. Each parameter has three levels such as internal pressure is $0.029,0.034$, $0.039 \mathrm{~N} / \mathrm{mm}^{2}$ and die stroke is $20,22,24 \mathrm{~mm}$. To get optimized parameters, applied the Taguchi's L9 orthogonal array. For 2 parameters and 3 levels the L9 orthogonal array is shown in Table 1.

Table 1 L9 ORTHOGONAL ARRAY

\begin{tabular}{|c|c|c|}
\hline Experiment & Parameter1 & Parameter2 \\
\hline 1 & 1 & 1 \\
\hline 2 & 1 & 2 \\
\hline 3 & 1 & 3 \\
\hline 4 & 2 & 1 \\
\hline 5 & 2 & 2 \\
\hline 6 & 2 & 3 \\
\hline 7 & 3 & 1 \\
\hline 8 & 3 & 2 \\
\hline 9 & 3 & 3 \\
\hline
\end{tabular}

For Experiment the tube material was 304 Stainless steel of diameter $(d)=75 \mathrm{~mm}$, thickness $(t)=0.3 \mathrm{~mm}$ and the fluid used in the experiment was water.

\section{RESULTS AND DISCUSSION}

The table 2 shows how the crown diameter varies over the die stroke increases when a constant internal pressure of $0.039 \mathrm{~N} / \mathrm{mm}^{2}$ by FEM.

Table 2 DIE STROKE VS CROWN DIAMETER

\begin{tabular}{|c|c|c|c|}
\hline $\begin{array}{c}\text { Die stroke } \\
(\mathbf{m m})\end{array}$ & $\begin{array}{c}\text { Internal } \\
\text { Pressure } \\
\left(\mathbf{N} / \mathbf{m m}^{\mathbf{2}}\right)\end{array}$ & $\begin{array}{c}\text { Crown } \\
\text { diameter } \\
\mathbf{( m m})\end{array}$ & $\begin{array}{c}\text { Percentage } \\
\text { of increase } \\
\mathbf{( \% )}\end{array}$ \\
\hline 20 & 0.039 & 129.842 & 29.842 \\
\hline 22 & 0.039 & 130.464 & 30.464 \\
\hline 24 & 0.039 & 131.685 & 31.685 \\
\hline
\end{tabular}

\begin{tabular}{|l|l|l|l|}
\hline 26 & 0.039 & 132.258 & 32.258 \\
\hline 28 & 0.039 & 133.356 & 33.356 \\
\hline 30 & 0.039 & 134.257 & 34.257 \\
\hline
\end{tabular}

The table 3 shows how the crown diameter varies over the internal pressure increases when a constant die stroke of $30 \mathrm{~mm}$ by FEM.

Table 3 INTERNAL PRESSURE VS CROWN DIAMETER
\begin{tabular}{|c|c|c|c|}
\hline $\begin{array}{c}\text { Internal } \\
\text { Pressure } \\
\left(\mathbf{N} / \mathbf{m m}^{\mathbf{2}} \mathbf{)}\right.\end{array}$ & $\begin{array}{c}\text { Die stroke } \\
\mathbf{( m m )}\end{array}$ & $\begin{array}{c}\text { Crown } \\
\text { diameter } \\
\mathbf{( m m})\end{array}$ & $\begin{array}{c}\text { Percentage } \\
\text { of increase } \\
\mathbf{( \% )}\end{array}$ \\
\hline 0.025 & 30 & 132.758 & 32.758 \\
\hline 0.029 & 30 & 133.310 & 33.310 \\
\hline 0.034 & 30 & 133.745 & 33.745 \\
\hline 0.039 & 30 & 134.257 & 34.257 \\
\hline 0.045 & 30 & 134.824 & 34.824 \\
\hline
\end{tabular}

The Figure 8 shows the plotted graph between crown diameters and die stroke. The Figure 9 shows the plotted graph between crown diameter and internal pressure.

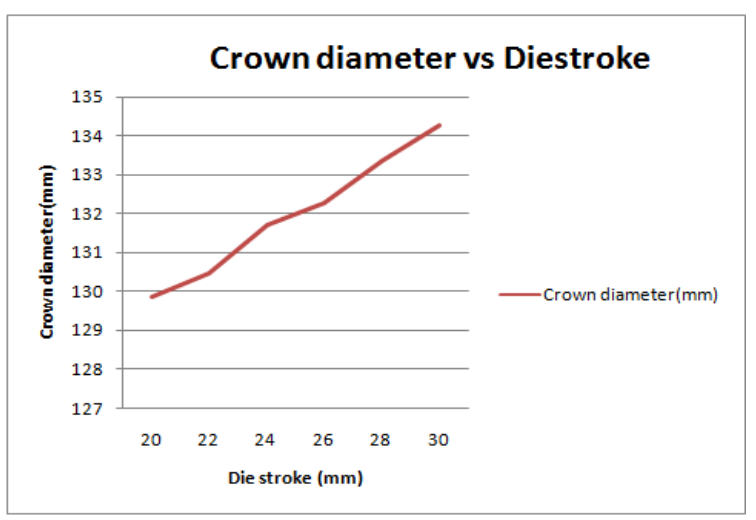

Figure 8 Crown diameter vs Die stroke

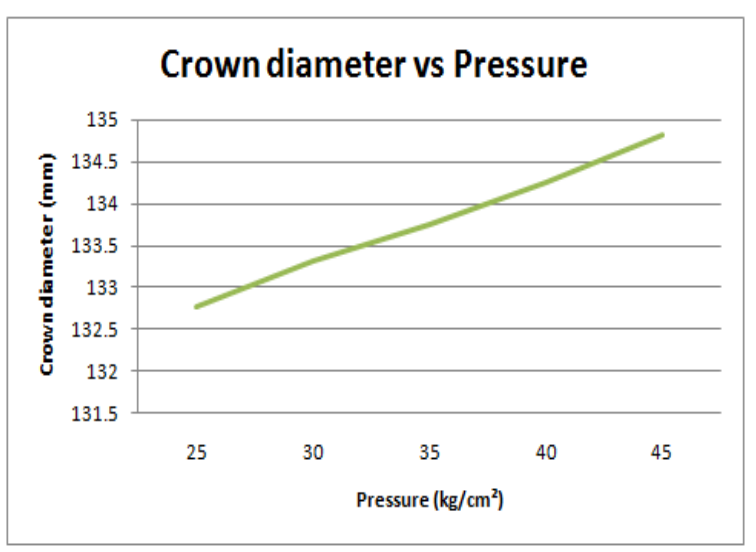

Figure 9 Crown diameter vs Internal Pressure 
The Figure 10 shows the stress distribution and final shape of the one convolution of the bellow for the die stroke $20 \mathrm{~mm}$ and internal pressure $0.039 \mathrm{~N} / \mathrm{mm}^{2}$.

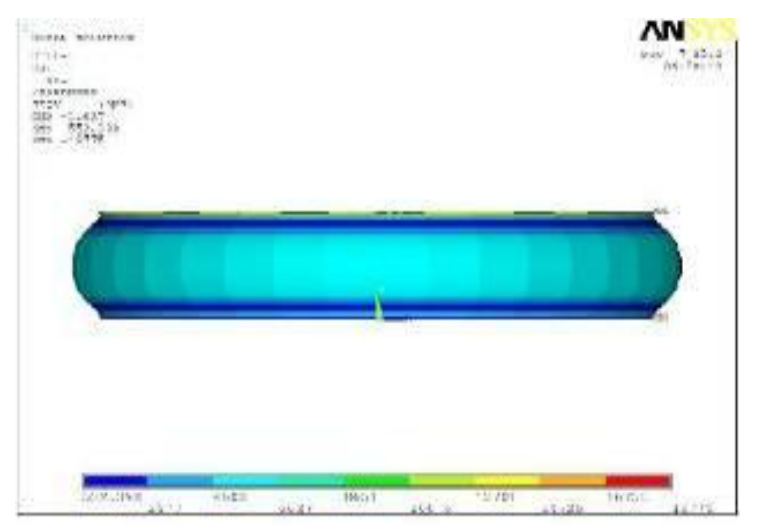

Fig. 10. Stress distribution

The Table 4 shows the results of the experiment and the fluid used in the experiment was water.

\begin{tabular}{|c|c|c|c|c|}
\hline $\begin{array}{c}\text { Experi } \\
\text { ment }\end{array}$ & $\begin{array}{l}\text { Pressure } \\
\left(\mathrm{N} / \mathbf{m m}^{2}\right)\end{array}$ & $\begin{array}{c}\text { Die } \\
\text { stroke } \\
(\mathrm{mm}) \\
\end{array}$ & $\begin{array}{l}\text { Crow } \\
\text { n dia } \\
(\mathrm{mm}) \\
\end{array}$ & Remark \\
\hline 1 & 0.029 & 20 & 92.18 & $\begin{array}{c}\text { No } \\
\text { bursting }\end{array}$ \\
\hline 2 & 0.029 & 22 & 93.42 & $\begin{array}{c}\text { No } \\
\text { bursting }\end{array}$ \\
\hline 3 & 0.029 & 24 & 94.74 & $\begin{array}{c}\text { No } \\
\text { bursting }\end{array}$ \\
\hline 4 & 0.034 & 20 & 95.28 & $\begin{array}{c}\text { No } \\
\text { bursting }\end{array}$ \\
\hline 5 & 0.034 & 22 & 96.20 & $\begin{array}{c}\text { No } \\
\text { bursting }\end{array}$ \\
\hline 6 & 0.034 & 24 & 97.22 & $\begin{array}{c}\text { No } \\
\text { bursting }\end{array}$ \\
\hline 7 & 0.039 & 20 & 97.78 & $\begin{array}{c}\text { No } \\
\text { bursting }\end{array}$ \\
\hline 8 & 0.039 & 22 & 98.14 & Bursting \\
\hline 9 & 0.039 & 24 & -- & $\begin{array}{c}\text { Not } \\
\text { conducted }\end{array}$ \\
\hline
\end{tabular}

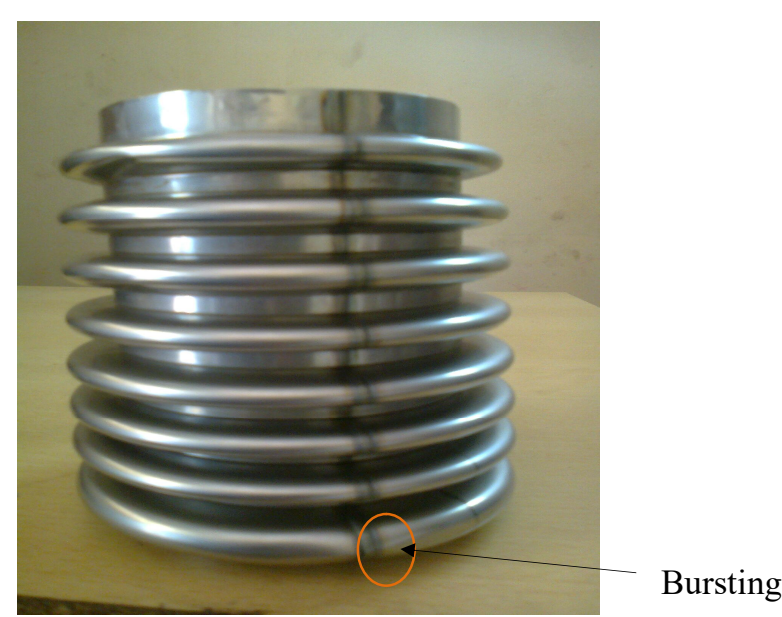

Fig. 11. Final product of the experiment

From the Table 4 the combination of die stroke 20 $\mathrm{mm}$ and internal pressure $0.039 \mathrm{~N} / \mathrm{mm}^{2}$ give the maximum crown diameter without bursting.

\section{A. Hardness test}

Hardness of the material before and after the process for various samples by conducting Vickers Hardness test are shown in Table 5.

Table 5 HARDNESS RESUlT

\begin{tabular}{|l|l|l|l|l|l|}
\hline \multicolumn{7}{|c|}{ H.V @ $0.5 \mathrm{Kg}$} \\
\hline $\begin{array}{l}\text { Before } \\
\text { Process }\end{array}$ & 144.5 & 143.7 & 145.7 & 144.3 & 145.4 \\
\hline $\begin{array}{l}\text { After } \\
\text { Process }\end{array}$ & 297.6 & 296.0 & 298.7 & 294.3 & 296.7 \\
\hline
\end{tabular}

Due to Hydroforming process the hardness value of the specimen increases by 100 percent.

\section{CONCLUSION}

In this study, the Hydroforming process was carried out in Stainless Steel material in the form of Bellows. From the analysis, it was observed that when the internal pressure increases, the crown diameter of the bellow increases. Similarly, when the die stroke increases, the crown diameter of the bellow also increases. In this study, the die stroke has more influence on crown diameter than the other parameter i.e., internal pressure. From the study, the combination of die stroke $20 \mathrm{~mm}$ and internal pressure $0.039 \mathrm{~N} / \mathrm{mm}^{2}$ give the maximum crown diameter without bursting. In this study, due to Hydroforming process the hardness of the Stainless Steel material increases by 100 percent. 


\section{REFERENCES}

[1] Ghader Faraji et al., (2008) Experimental and finite element analysis of parameters of metal bellows. Int J Adv Manuf Technol., 38, 641-648.

[2] G.H. Faraji et al., (2009) Evaluation of effective parameters in metal bellows forming process. Journal of Material Processing Tech., 209, 3431-3437.

[3] Rajiv Selvam et al., (2011) A Study and Analysis on Electromagnetic Compression Forming Processed Aluminium Alloy Tubes. Advanced Materials Research, 337,560-563.

[4] G.H. Majzoobi et al (2007). Prediction of failure in tube hydroforming process using a damage model. Journal of Mechanical Science and Technology, 21,1512-1517.

[5] Satoshi I, Hiroshi K, Masanori K (2000) Evaluation of mechanical behavior of new type bellows with two directional convolutions. $\mathrm{NuCl}$ Eng Des, 197, 107-114.

[6] S.W. Lee (2002) Study on the forming factor of metal bellows. Journal of Material Processing Tech., 130-131, 47-53.

[7] N. Sivaprasad Varma et al (2008) A numerical study of loading conditions on tubular hydroforming. Journal of Material Processing Tech., 196, 174-183.

[8] A. Alaswad, A.G. Olabi, K.Y. Benyounis (2011). Tube hydroforming process: A reference guide. Materials and Design, 33, 328-339.

[9] Rajiv Selvam et al (2012) Finite Element Analysis of Electromagnetic Compression forming of steel tubes. Procedia Engineering ,38, 2520-2524.

[10] Koç, M. (Ed.). (2008). Hydroforming for advanced manufacturing. Elsevier. 